\title{
Automatic crater detection by mining existing crater map
}

\author{
Cheng-Zhi QIN ${ }^{\text {a, b, }}$ *, Yan-Wen WANG ${ }^{\text {a, b }}$, Wei-Ming CHENG $^{\text {a, b }}$, A-Xing ZHU ${ }^{\text {a, c, d }}$ \\ ${ }^{a}$ State Key Laboratory of Resources and Environmental Information System, Institute of Geographic Sciences and Natural \\ Resources Research, CAS, Beijing 100101,China,qincz@lreis.ac.cn,wangyw@lreis.ac.cn, chengwm@lreis.ac.cn, \\ axing@lreis.ac.cn \\ ${ }^{b}$ College of Resources and Environment, University of Chinese Academy of Sciences, Beijing 100049, China \\ ${ }^{c}$ Jiangsu Center for Collaborative Innovation in Geographical Information Resource Development and Application and School of \\ Geography, Nanjing Normal University, Nanjing 210097, China \\ ${ }^{d}$ Department of Geography, University of Wisconsin-Madison, Madison, WI 53706, USA \\ * Corresponding author
}

Keywords: Crater map, Crater detection approach, Digital terrain analysis, Random forests

\begin{abstract}
:
Existing geomorphologic type maps manually delineated by experts contain implicit expert knowledge on the spatial structure of real geomorphologic objects. Taking crater map as example, this study presents an attempt of mining the implicit expert knowledge contained in existing crater maps to automatically detect craters from digital elevation models (DEMs) of an area with similar environment as the area of the crater map.

The proposed automatic crater detection approach trains random forests classifiers based on existing crater map of an area and the spatial structural information derived by digital terrain analysis on DEM in the corresponding area, and then applies the trained classifiers to the application area with DEM.

A case study with the Lunar Orbiter Laser Altimeter (LOLA) crater map (Head et al., 2010) and Chang'E-1 lunar DEM (Li et al., 2010) with a resolution of $500 \mathrm{~m}$ shows that the proposed approach performed better than AutoCrat (Stepinski et al., 2009; 2012), a representative of existing crater detection approaches based on digital terrain analysis which have not effectively considered the spatial structural information of real craters.
\end{abstract}

